\title{
Os planos de historicidade na interpretação do Brasil de Sérgio Buarque de Holanda*
}

\author{
The planes of historicity of Sérgio Buarque de Holanda's interpretation \\ of Brazil
}

Thiago Lima Nicodemo

tnicodemo@gmail.com

Pós-doutorando

Instituto de Estudos Brasileiros - USP

Edifício Brasiliana - Praça do Relógio Solar no 342 - Cidade Universitária

05508-050 São Paulo - SP

Brasil

\section{Resumo}

Este artigo tem como objetivo a identificação dos mecanismos temporais fundamentais subjacentes à interpretação do Brasil na obra de Sérgio Buarque de Holanda, concentrando-se em seus textos publicados ao longo de uma década - da segunda edição de Raízes do Brasil (1948) a Visão do Paraíso (1958), incluindo Caminhos e Fronteiras (1957) e o manuscrito póstumo, produzido na primeira metade da década de 1950, Capítulos de Literatura Colonial. Procuro mostrar a relação entre o processo de especialização e profissionalização do autor como historiador, ocorrido em fase posterior à publicação de Raízes do Brasil (1936), e o desenvolvimento de um mecanismo de rearticulação do tempo histórico. Este mecanismo não é apenas relacionado com a articulação em protenção e retenção de passado e futuro, mas é disposto em um esquema de natureza analógica ou figural. 0 resultado disto é uma combinação entre um horizonte técnico historiográfico e um horizonte político que dá contornos peculiares à interpretação do Brasil de Sérgio Buarque de Holanda.

\section{Palavras-chave}

Sérgio Buarque de Holanda; Historiografia brasileira; Teoria da história.

\begin{abstract}
The purpose of this article is to identify the fundamental temporal mechanisms of Sérgio Buarque de Holanda's interpretation of Brazil, focusing on his texts published over a decade - from Raízes do Brasil (1948) to Visão do Paraíso (1958), including Caminhos e Fronteiras (1957) and the posthumous manuscript conceived in the early 1950s, Capítulos de Literatura Colonial. My intention is to show the relationship between the process of specialization and professionalization experienced by the author as a historian, which took place following the publication of Raízes do Brasil (1936), and the outline of a peculiar mechanism of articulation of the historical time in his texts. This mechanism is not only related to the articulation of past and future in protention and retention, but is also arranged in an analogic or figural scheme. The result is a combination of a technical-historiographical horizon and a political horizon, typical of Sérgio Buarque de Holanda's interpretation of Brazil.
\end{abstract}

\section{Keywords}

Sérgio Buarque de Holanda; Brazilian historiography; Theory of history.

Recebido em: 4/6/2013

Aprovado em: 28/10/2013

\footnotetext{
* Este artigo é uma versão aprimorada da reflexão que venho desenvolvendo nos seguintes trabalhos: NICODEMO 2011; 2014.
} 
Por ocasião da publicação da segunda edição da obra Sobrados e Mocambos, de Gilberto Freyre, Sérgio Buarque de Holanda realizou a crítica "Sociedade Patriarcal", nos rodapés do jornal Diário Carioca, ${ }^{1}$ em 1951. Na série de artigos, louvou as dimensões monumentais do projeto de Freyre de compreensão da sociedade patriarcal no Brasil que seria composto dos volumes Casa Grande e Senzala, Sobrados e Mocambos, Nordeste, Ordem e Progresso e do jamais publicado, Jazigos e Covas Rasas, mas realizou duras críticas aos resultados até então apresentados.

De início, apontou que o pensamento de Freyre era movido "por um intenso calor afetivo", sendo sua visão da sociedade patriarcal, "nostálgica" e "amorosa", ainda marcada "por certos valores e estilos tradicionais" do que fora no passado o latifúndio canavieiro fundado no trabalho escravo (HOLANDA 1979, p. 101). Mesmo reconhecendo a diversidade social e cultural do Brasil, a interpretação de Freyre era exageradamente apoiada na ideia "do regime da economia patriarcal", ideia que servia ao autor pernambucano como modelo interpretativo de toda a formação histórica brasileira (HOLANDA 1979, p. 102).

Na visão de Sérgio Buarque, a interpretação de Freyre era viciada por uma confusão de ordem metodológica entre "forma" e "conteúdo" social, questão que remetia diretamente à sociologia de Georg Simmel. Enquanto o sociólogo alemão tendia à depuração de conceitos e princípios de natureza sociológica a partir do estudo de fenômenos históricos concretos, Freyre tendia a embaralhar ou inverter o processo, de maneira que "instrumentos de exposição, distinção, confronto, análise, convertem-se em realidades mais ou menos empíricas, servindo de base para julgamentos de valor que mal se disfarçam" (HOLANDA 1979, p. 106).

Nas críticas de Sérgio Buarque reverberam algumas das linhas mestras do seu próprio pensamento, em especial alguns dos fundamentos de sua obra de estreia, Raízes do Brasil, publicada em 1936. Nesta obra as categorias analíticas - ou "tipos" - são extraídas de formas determinadas pela experiência colonial e universo mental português. ${ }^{2}$ Estas formas só assumem características singulares na medida em que se moldam de acordo com a necessidade, segundo um princípio de completa inoperância, desleixo e recusa de projeção racional (GOLDFEDER; WAIZBORT 2009, p. 29). A formação nacional se dá, portanto, no descompasso produzido pela adaptação de formas europeias no território americano. Dito isso, pode-se compreender melhor a crítica a Freyre, pois o patriarcalismo não deveria ser encarado como característica típica da formação brasileira. Como forma europeia, pertencia à cultura metropolitana de matriz barroca, sendo, por isso, forma, e não o conteúdo do processo social de formação nacional (HOLANDA 1979, p. 104).

Estes comentários são intrigantes, pois reforçam o argumento central de Raízes do Brasil pouco tempo depois do autor ter realizado uma revisão profunda

\footnotetext{
${ }^{1}$ A série de artigos foi originalmente publicada nas páginas do Diário Carioca, 4, 13 e 18 de novembro de 1951, sob o título de, respectivamente, "Sociedade Patriarcal I", "Sociedade Patriarcal II", "Sociedade Patriarcal, Conclusão". Posteriormente publicados em 1979 na obra Tentativas de Mitologia (HOLANDA 1979, p. 99-110).

2 Sobre a incidência do termo "forma" e suas variantes, ver EUGÊNIO 2011, p. 339-353.
} 
no livro, revendo ou matizando muitos de seus argumentos, para a publicação da segunda edição, em 1948. Após publicar Raízes do Brasil, o historiador brasileiro se especializou como historiador de ofício, processo que, segundo ele próprio, foi impulsionado por experiências como a de docente na recém-criada Universidade do Distrito Federal e pelo contato intenso com professores como Henri Hauser e Henri Tronchon (CARVALHO 2003, p. 181-182).

A bibliografia já clássica sobre o Sérgio Buarque de Holanda defende a ideia de que a proximidade com a universidade produz efeitos também em sua escrita. Na medida em que se torna um historiador profissional o autor substitui o recurso ao ensaio por textos mais especializados, com recortes consideravelmente mais circunscritos. Isso pode ser percebido, por exemplo, no modo como os modelos interpretativos duais de seu primeiro livro, "trabalhador e aventureiro", ou, o "ladrilhador e semeador", alteram-se desde Monções, seu segundo livro publicado em 1945, e resulta no desenvolvimento de um método fluido, preocupado em escapar de generalizações e em captar as diversas temporalidades dos eventos.

\section{A revisão de Raízes do Brasil}

As revisões feitas para a segunda e terceira edições de Raízes do Brasil, respectivamente publicadas em 1948 e em 1956 têm relação direta com a transformação de Sérgio Buarque em historiador especializado. A revisão para a segunda edição é ampla e radical - segundo cálculo realizado por João Kennedy Eugênio em estudo recente, foram inseridos 116 novos parágrafos, o que corresponde a um acréscimo da ordem de um terço do texto. Fundamentalmente, a revisão se pautou por um abrandamento da matriz sociológica da obra e por um adensamento do aparato de erudição histórica (EUGÊNIO 2011, p. 400-408); ao mesmo tempo em que eclipsou a influência originalmente exercida por Freyre, segundo hipótese de João Cezar de Castro Rocha (ROCHA 2008, p. 248-249). Correndo o risco de algum esquematismo, pode-se afirmar que Sérgio atenua ou extingue julgamentos que atribuem positividade ao resultado do processo de colonização (EUGÊNIO 2011, p. 375$378 ; 386)$.

As modificações realizadas para a terceira edição, que estabeleceu o texto definitivo, são pontuais, muito menos numerosas, e reforçam em alguns pontos, muito significativos, o sentido estabelecido na segunda revisão. Um exemplo, já notado por Castro Rocha (ROCHA 2008, p. 247), é a modificação no parágrafo de abertura da primeira edição:

Todo estudo compreensivo da sociedade brasileira há de destacar o fato verdadeiramente fundamental de constituirmos o único esforço bem-sucedido em larga escala, de transplantação da cultura europeia para uma zona de clima tropical e subtropical. Sobre território que, povoado com a mesma densidade da Bélgica, chegaria a comportar um número de habitantes igual ao da população atual do globo, vivemos uma experiência sem símile. Trazendo de países distantes nossas formas de convívio, nossas instituições, nossas ideias, e timbrando em manter tudo isso em ambiente muitas vezes desfavorável e hostil, somos ainda 
hoje desterrados em nossa terra. Podemos construir obras excelentes, enriquecer nossa humanidade de aspectos novos e imprevistos, elevar à perfeição o tipo de civilização que representamos: o certo é que todo o fruto de nosso trabalho ou de nossa preguiça parece participar de um sistema de evolução próprio de outro clima e de outra paisagem.

Na terceira edição, de 1956, a mesma passagem toma a seguinte forma,

A tentativa de implantação da cultura europeia em extenso território, dotado de condições naturais, se não adversas, largamente estranhas à sua tradição milenar, é, nas origens da sociedade brasileira, o fato dominante e mais rico em consequências. Trazendo de países distantes nossas formas de convívio, nossas instituições, nossas ideias, e timbrando em manter tudo isso em ambiente muitas vezes desfavorável e hostil, somos ainda hoje desterrados em nossa terra. Podemos construir obras excelentes, enriquecer nossa humanidade de aspectos novos e imprevistos, elevar à perfeição o tipo de civilização que representamos: o certo é que todo o fruto de nosso trabalho ou de nossa preguiça parece participar de um sistema de evolução próprio de outro clima e de outra paisagem.

Na reescrita dos parágrafos se pode observar que o autor acentua a ideia de um descompasso entre "forma" e "conteúdo", enfatizando que a formação do Brasil ocorreu sem obedecer um plano claramente definido, mas é resultado de um processo de adaptação ainda incompleto (GOLDFEDER; WAIZBORT 2009, p. 29). Nas palavras de João K. Eugênio, "a meta a ser atingida pela cultura não é isto ou aquilo, mas o desenvolvimento das próprias potencialidades: chegar a ser o que é; atualizar a forma" por meio da adaptação (EUGÊNIO 2011, p. 351352). A forma nacional se dá, portanto, pelo negativo, por uma busca dada pela ausência de procura.

Esse descompasso nada mais é do que um mecanismo temporal de articulação entre passado e presente. De um lado, isso se faz mediante a inserção de um "hoje" ou "agora" que reforça a estrutura retrospectiva de toda 'formação', e assim se investiga como algo tomou a forma com que conhecemos em nosso presente. Não é por acaso que Sérgio Buarque reforça justamente isso em seu comentário a Freyre: "guardadas as proporções devidas, o senhor de engenho ou antepassado do "coronel" do sertão, ao menos nos séculos XVIII e XIX, não se distinguiriam muito, social ou psicologicamente, dos nobres e fidalgos do Reino" (HOLANDA 1979, p. 104). De outro lado, com a inserção não menos importante de um "ainda" no sentido em que este processo de formação segue em curso, não foi terminado.

Há uma forte relação entre o delineamento de um mecanismo fundamental de configuração temporal e as implicações políticas em Raízes do Brasil. A obliteração da influência freyriana, assim como o apagamento de trechos que sugerem uma visão otimista da empreitada colonial, dão lugar a um tom progressista e democrático. Neste sentido, a análise da modificação no parágrafo inicial da obra, apesar de ocorrida apenas na terceira edição ajuda muito a compreender o sentido das modificações nos marcadores temporais introduzidas pelo autor em 1948. A compilação de modificações na segunda 
edição realizada por João K. Eugênio, que pode ser vista abaixo, mostra algumas inserções que confluem no sentido do reforço de uma dinâmica da análise da formação nacional como um processo ainda incompleto,

Tendo dito que "uma superação da doutrina democrática só será possível entre nós quando tenha sido vencido a antítese liberalismo-caudilhismo" ( $2^{a}$ ed., p. 101) Sérgio adianta, de forma enfática, que "essa vitória nunca se consumará enquanto não se liquidem, por sua vez, os fundamentos personalistas e, por menos que o pareçam aristocráticos, onde ainda assenta nossa vida social ( $2^{\mathrm{a}}$ ed., p. 269). Ele acrescenta que, "se o processo revolucionário a que vamos assistindo [...] tem um significado claro, será a dissolução lenta, posto que irrevogável, das sobrevivências arcaicas, que o nosso estatuto de país independente até hoje não conseguiu extirpar" ( $2^{\text {a }}$ ed., p. 269-270). De fato, "somente através de um processo semelhante teremos finalmente revogada a velha ordem colonial e patriarcal, com todas as suas consequências morais, sociais e políticas que ela acarretou e continua a acarretar" (EUGÊNIO 2011, p. 388, grifos no original).

Raízes do Brasil é composto por uma sobreposição de planos interpretativos rivais ou contraditórios, de uma "metodologia dos contrários", como ressaltou Antonio Candido em seu conhecido prefácio à obra. No entanto, fica patente que nas revisões para as edições seguintes, especialmente na segunda, o autor atenua essa dialética, imprimindo uma coerência ao texto que estava ausente na versão original. Se na primeira edição éramos paradoxalmente ao mesmo tempo "bem sucedidos" e "desterrados" (ROCHA 2008, p. 249), seremos, com essa mudança, governados apenas pela última metáfora, a do desterro. O apagamento da referência a Freyre segue a reboque deste movimento de anulação da visão otimista da empreitada colonial.

Com isso, é reforçada também uma estrutura temporal protendida entre presente e passado, de um "horizonte de expectativa" (KOSELLECK 2006) marcado pela força expressiva do advérbio "ainda" ou melhor, "ainda não", como se pode ver claramente nos trechos em negrito da citação acima. A formação do Brasil moderno só se dará com a "dissolução irrevogável das nossas sobrevivências arcaicas". Nesse sentido, retomando sua crítica a Freyre de 1951, não basta reconhecer que o "senhor de engenho" é o antepassado do atual "coronel", é necessário reconhecer que essa relação representa uma reminiscência daninha para a formação de uma sociedade moderna, que deve ser extirpada para o desenvolvimento desta.

Dialogando com a tese de João K. Eugênio, de fato, a matriz organicista do livro, talvez o seu fundamento mais importante, é seriamente atenuada entre as edições da obra. Originalmente, Sérgio Buarque de Holanda acreditava que as formas sociais e culturais deveriam se desenvolver de modo espontâneo até tomarem formas nacionais próprias (EUGÊNIO 2011, p. 359). Não basta apenas reconhecer a autenticidade desta "experiência sem símile" e da forte perspectiva de continuidade desse processo segundo uma análise organicista - o horizonte reforçado no livro na segunda edição é diametralmente oposto a este, pois preconiza uma ruptura com nossas formas históricas, projetada como expectativa em relação ao futuro. 
O último capítulo da obra, "Nossa Revolução" é o que sofre de forma mais aguda as consequências dessas modificações variantes do "ainda". A modificação no segundo parágrafo do capítulo é sintomática e pode resumir essa questão: Nas palavras de Sérgio, na primeira edição: "A grande revolução brasileira não foi um fato que se pudesse assinalar em um instante preciso; foi antes um processo demorado e que durou pelo menos três quartos de século"; se transforma a partir da segunda edição em "A grande revolução brasileira não é um fato que se pudesse assinalar em um instante preciso; foi antes um processo demorado e que vem durando pelo menos três quartos de século" (HOLANDA 1948, p. 254, grifos meus). "Nossa revolução" representa a ruptura com o passado arcaico presente desde a primeira edição da obra, mas a partir das modificações publicadas em 1948 a obra ganha uma pretensão temporal complexa e, como veremos a seguir, eminentemente moderna.

Não se pode tratar, portanto, de Raízes do Brasil sem levar em consideração as profundas modificações realizadas entre as edições de 1936, 1948 e 1956; sobretudo porque estas modificações alteraram muito de nossa percepção atual sobre a obra. $O$ que se deve acrescentar para além do que já se sabe sobre essas modificações é o fato de que o desenvolvimento do historiador profissional ocorrido ao longo da década de 1940 impulsiona grande parte destas alterações. De um ponto de vista técnico, estas modificações o reforçam uma estrutura temporal protendida entre experiências do passado e expectativas do futuro ainda inconcluso.

Por outro lado, não se pode deixar de reconhecer que esta ideia tem profundas implicações políticas, já que acentuam o caráter progressista e democrático da obra (EUGÊNIO 2011, p. 395-396). O famoso prefácio de Antonio Candido a Raízes, do final da década de 1960 contribui para reforçar esta mesma dimensão, sem considerar que certas ideias reelaboradas em 1948 e 1956 não se apresentavam de forma tão clara na primeira edição da obra. Não foi casual que este prefácio se constituiu numa espécie de paradigma, influenciando muitas outras interpretações da obra de Sérgio Buarque de Holanda.

\section{A ideia de formação: uma teleologia sem anacronismo}

O crítico Roberto Vecchi assinalou que, na estrutura temporal desenvolvida por Sérgio Buarque de Holanda, o tempo presente opera como um resto que determina a condição contemporânea do Brasil. No plano do presente se chocam ou se sobrepõem reminiscências do passado arcaico e os arroubos progressistas condicionados pela expectativa de um futuro moderno (VECCHI 2005, p. 169). Em suas palavras: "o presente é forjado por essa dobra que é simultaneamente inscrita nas duas temporalidades formando a temporalidade nacional" (VECCHI 2005 , p. 168). Como observa o mesmo crítico, o termo revolução não deve ser compreendido no seu sentido contemporâneo de ruptura radical. A nossa revolução, além de lenta e gradual, só ganha sentido pleno se aproximada de seu significado etimológico de revolvere, "rolar para atrás ou enrolar", nos fluxos e refluxos de passado e futuro experenciados no presente.

A modificação operada pelo horizonte do "ainda" imprime um inequívoco sentido teleológico na análise histórica de modo que o passado arcaico passa 
a ser considerado sob o ponto de vista da sua superação rumo à redenção moderna. O leitor de hoje, formado em nossa tradição de pensamento social, tende provavelmente a encarar este procedimento com naturalidade, ou ao menos familiaridade; mas cumpre observar que se trata de uma notável operação de imputação de elementos imaginários, de uma "ficcionalização" da análise histórica (AGAMBEN 2000, p. 38-39).

Pode parecer contraditório sustentar que as modificações em Raízes do Brasil possuam um sentido "estetizante" ao mesmo tempo em que se defende que o rigor historiográfico da obra aumenta - mas o argumento que estou a defender é exatamente este. As modificações "estetizantes" ou "ficcionalizantes", que configuram os eventos e processos históricos no passado baseados em um anseio projetado no futuro, são instrumentalizadas para um aumento de rigor histórico na obra, de modo que o autor se emparelha com a vanguarda da historiografia profissional do período. O primeiro e mais importante indício disto é que ao tratar do processo de formação do Brasil como um ainda, ou melhor, um ainda não, o autor procura justamente anular a nação como pressuposto teleológico da narrativa histórica, típico da tradição historiográfica novecentista. Afinal, é apenas com a superação do passado arcaico de origem ibérica que temos condições de nos constituirmos como uma cultura e sociedade próprias.

Outro aspecto importante é o da subjetivação do autor/narrador no texto. Ao deslocar o telos do discurso histórico, da nação pressuposta como dado, para o horizonte futuro de um processo em curso, o narrador passa a participar ativamente do processo narrado. O ainda não indica o anseio de que a cultura se emancipe e a nação moderna se forme. Esta postura rompe com o objetivismo científico, também estabelecido no século XIX, que tem como pressuposto a imparcialidade da análise e a consequente obliteração da presença do narrador na obra.

Neste ponto é necessário retomar o paralelo entre o paradigma temporal do ainda não e a estrutura do tempo messiânico. A protensão temporal implicada pelo ainda não provoca um efeito de "inefetividade teleológica", ou seja, o evento aguardado não deve se cumprir, ainda mais se levando em conta a evolução dos processos históricos que vem do nosso passado (AGAMBEN 2000, p. 41).

Reside justamente aí a força dessa construção, numa espécie de desnaturalização contingencial do passado. A esperança de superação das raízes no futuro é acompanhada por um certo inconformismo com o passado que legitima a ação no plano do hoje - o que aconteceu poderia não ter acontecido se tivéssemos tomado decisões diferentes, a história poderia ter sido outra. Sob este prisma, a análise empreendida no texto corrobora o próprio processo narrado pois a identificação de nossas raízes arcaicas é o passo fundamental para que possamos superá-las. Assim também a obra é reforçada em sua dimensão intertextual, como mecanismo aberto, que pressupõe a completude de um ciclo no ato da leitura - recurso, aliás, típico da literatura de vanguarda.

Já tive oportunidade de observar que em comentários feitos por conta da edição de Apologia da história de Marc Bloch, Sérgio Buarque demonstra forte afinidade com a concepção de história do autor francês, advogando em prol de uma concepção de história enraizada no presente e por isso engajada. A ideia 
principal defendida por Sérgio é que a história modernizada e universitária que se desenvolvia àquela altura no Brasil deveria ser combativa em relação aos seus próprios usos autoritários e nacionalistas (NICODEMO 2008, p. 34-42). Por isso, é inevitável considerar que entre as duas edições de Raízes do Brasil, entre 1936 e 1948, o autor vivenciou a derrocada dos totalitarismos, incluindo a ditadura estado-novista, e a $2^{\text {a }}$ Guerra Mundial.

Em Sérgio Buarque de Holanda o conluio entre historicidade e política na análise da formação do Brasil é particularmente evidente devido, como mostrei, ao desejo de dar coerência e inteligibilidade ao seu próprio legado, ao nível de domínio técnico da temporalidade e também ao seu nível de consciência histórica como agente. Entretanto, é necessário ressaltar que ele não é o único a compartilhar essa visão de mundo e a desenvolver ferramentas conceituais adaptadas àquela realidade. Uma análise histórica enredada nos dilemas do presente e ela própria comprometida com os processos que são seus objetos privilegiados de análise são a marca característica do desenvolvimento das ciências sociais brasileira, desde o ensaísmo dos anos 1930. O esforço de anulação do telos nacional e sua substituição por uma articulação protendida do tempo entre passado e futuro, subjetivação do autor/narrador, e o uso de arcabouço conceitual em favor da aceleração do próprio processo narrado estão presentes em obras aparentemente díspares como Formação do Brasil Contemporâneo, de Caio Prado Jr., Formação da Literatura Brasileira, de Antonio Candido; Formação Econômica do Brasil, de Celso Furtado, dentre outras. Talvez compreendendo melhor como estas características comuns são trabalhadas em textos fundamentais do nosso pensamento social possamos abrir caminho para trata-las como uma inflexão paradigmática; ou melhor, como uma concepção brasileira de história.

\section{Primeiro interregno: nasce um historiador profissional}

Se a revisão de Raízes do Brasil foi uma espécie de acerto de contas com o seu próprio tempo, entre historiografia e política, como então evolui a arquitetura teórica do pensamento de Sérgio Buarque de Holanda para além de sua obra de estreia? Para responder esta questão é necessário considerar que na época em que revisou Raízes o autor passava por um período intelectualmente muito produtivo e profissionalmente agitado. Mudou-se em 1946 do Rio de Janeiro, onde residira desde 1920, para São Paulo, sua cidade natal, assumindo a direção do Museu Paulista e, quase de imediato, implantando sérias reformas modernizantes na instituição. Intelectualmente, Sérgio havia acabado de publicar Monções, em 1945, no ano seguinte, Cobra de Vidro, coletânea de artigos de jornal do início da década de 1940, e estava começando a pesquisar e a publicar os textos que foram unidos, alguns anos depois, em 1957, como Caminhos e Fronteiras.

Monções e Caminhos e Fronteiras tratam da formação de uma dinâmica social interna impulsionada pela expansão do território na América portuguesa a partir de São Paulo colonial, processo que culminou com a fundação e colonização de povoados como o de Cuiabá. Enquanto Monções enfoca a expansão ocorrida 
principalmente no do século XVIII para fins comerciais a partir de redes fluviais, Caminhos e Fronteiras se concentra nas entradas e bandeiras dos séculos XVI e XVII. Trata-se de estudos muito menos abrangentes do que seu primeiro ensaio, concebidos em diálogo com a vanguarda da ciência histórica do período na medida trabalham na reconstituição da dimensão quotidiana da vida dos agentes, levando em consideração a cultura material, hábitos, alimentação, indumentária; incluindo também a dimensão da produção agrícola e manufatureira, costumes e universo de crenças. Foi, aliás, graças a esses trabalhos que Sérgio Buarque chamou a atenção de Fernand Braudel e Lucien Febvre sendo convidado por eles a dar um curso na Universidade de Paris, e que resultou na publicação de um artigo na revista dos Annales (HOLANDA 1950).

De um modo bastante geral, a ideia base de Raízes do Brasil de que a formação nacional resulta na adaptação de formas europeias no território americano é testada e aprimorada no estudo específico dos bandeirantes e dos monçoeiros. Por meio da história capitaneada por essas figuras é possível acompanhar como o ímpeto aventureiro típico do colonizador vai aos poucos se assentando em formas sociais características. Como diz o historiador na introdução de Monções, para formar-se, a civilização adventícia é "colocada perante contingencias do meio, pode aceitar, assimilar e produzir novas formas de vida, revelando-se até certo ponto criadora e não só conservadora de um legado tradicional nascido em clima estranho" (HOLANDA 1990, p. 13; WEGNER 2000, p. 219). Essa população inicialmente originada dos colonizadores se mesclou com a população nativa assim como teve que adaptar seus modos de vida em seus mais diversos aspectos, como os hábitos alimentares, o aproveitamento dos caminhos e trilhas, as técnicas de navegação fluvial, dentre outros.

A interiorização ou expansão das fronteiras da América portuguesa representa uma espécie de "brecha" no sistema colonial na visão de Sérgio Buarque de Holanda (WEGNER 2000, p. 218). A sociedade resultante dessas interações no planalto paulista nasce como que por descuido dos desígnios metropolitanos, direcionados, como se sabe, ao enriquecimento rápido através da venda de gêneros agrícolas no mercado europeu. Isso nos projeta novamente no diálogo entre o autor e Gilberto Freyre no início da década de 1950, afinal para Sérgio Buarque, o regime patriarcal não poderia representar adequadamente a formação histórica do Brasil. Em primeiro lugar porque a realidade de uma região não poderia ser proposta como chave interpretativa de outras tão distintas como a paulista. Em segundo lugar, porque o patriarcalismo não era uma forma nascida na América, mas sim um conjunto de características socioculturais ibéricas. A isso se contrastavam exemplos do desenvolvimento de formas autóctones como as produzidas pela cultura do bandeirante e do monçoeiro.

\section{Os planos de historicidade da interpretação do Brasil}

Diante do que foi estabelecido até aqui sobre a estrutura temporal da interpretação do Brasil feita por Sérgio Buarque de Holanda, não se pode deixar de questionar como é possível então não igualar o nascimento de uma civilização como a configurada em Monções e Caminhos e Fronteiras à tomada de forma 
da nação brasileira? Em outras palavras, como é possível falar da formação da nacionalidade sem tê-la como pressuposto da escrita da história, sem incorrer em um anacronismo?

Subsídios para responder a questão podem ser encontrados numa das camadas da crítica de Sérgio Buarque de Holanda a Gilberto Freyre a que me referi no início do artigo; afinal, no limite, o que foi questionado é a pertinência do patriarcalismo como elemento explicativo de nossa sociedade nacional, portanto, desde o século XIX. No questionamento subjazem dois planos sobrepostos não redutíveis - um é o da dialética entre elementos ibéricos e elementos autóctones no processo de colonização, que inclui a ideia da família patriarcal (dentre outros traços da mentalidade europeia distinguidos na crítica pelo termo geral "barroco"). Outro plano é o da análise do papel que esses elementos, já característicos de uma lógica própria, foram reaproveitados ou rearranjados na formação do estado e da nação brasileira, processo ocorrido ao longo do século XIX e que se desdobra até o momento presente em que vivem os intelectuais.

Não se trata, portanto, de um único corte, de uma simples dobra entre passado e futuro que enreda o presente. O olhar do leitor contemporâneo, treinado e formado na própria tradição do pensamento social brasileiro, naturaliza esta relação entre planos temporais, lendo os dois como se fossem um só. A própria fortuna crítica sobre o autor não considera esta especificidade e acaba com frequência por embaralhar as temporalidades. O mecanismo temporal que resumi pela introdução de um ainda, ou ainda não, reforçado na segunda edição de Raízes do Brasil é constituído, portanto, pela interação dessas duas temporalidades distintas.

Já foram adequadamente apontadas pela crítica as continuidades estruturais entre duas das figuras fundamentais de Raízes do Brasil: a aventura e a cordialidade (MONTEIRO 1999, p. 172). Enquanto a metáfora do aventureiro remete esquematicamente ao colonizador lusitano, em seu afã por riqueza fácil e lucro imediato, em seu desinteresse de deitar raízes na terra explorada (MONTEIRO 1999 p. 102-110), o homem cordial, corresponde à herança de práticas patriarcais, ligadas ao meio rural, no desenvolvimento do Estado nacional no século XIX. Falando em termos que só ganham total clareza com a segunda edição de Raízes, a cordialidade é a herança, o produto da ação do espírito de aventura. O leitor já pode intuir que as implicações de uma herança colonial estão em estreita conformidade com o corte das duas temporalidades operado pelo ainda não. Tanto isso é verdade, que com a segunda edição da obra emerge um novo título para um capítulo bastante modificado que discute os impasses da ordem escravocrata no século XIX: "Herança Rural".

Ultrapassaria os limites deste texto refletir com profundidade sobre a evolução da ideia de herança na obra do autor, mas é interessante observar que o resultado do mecanismo é justamente propor de modo claro um descompasso entre processo de independência política e desenvolvimento de laços em comum, ou seja de uma nação que é construída historicamente, e não pressuposta teleologicamente como podemos observar em célebre texto de 1961, "A herança colonial, sua desagregação". O texto problematiza o descompasso entre processo 
de emancipação política e a criação de vínculos nacionais. Estas tendências, em suas próprias palavras, "não nascem juntas e, por longo tempo ainda, não caminham de mãos dadas" (HOLANDA 1961, p. 9).

Esta percepção pode levar a um enquadramento excessivamente esquemático das obras de Sérgio Buarque de Holanda, já que Monções e Caminhos e Fronteiras (assim como Visão do Paraíso) tendem a tratar de processos históricos ocorridos no primeiro plano temporal, aquele que contempla o nascimento de uma cultura com traços próprios na tensão entre elementos ibéricos e elementos autóctones no processo de colonização; enquanto Raízes do Brasil e outros textos do autor que tratam do século XIX, como, por exemplo, Do Império à República, de 1972, se dedicam aos temas da pertinência da herança colonial e dos impasses gerados por tal herança na formação do estado e da nação brasileira. Para além de simplesmente complementares, esses dois planos de historicidade estão sempre em interação na obra do autor. Normalmente a presença em primeiro plano de uma destas dimensões remete por analogia a uma outra dimensão temporal, mais ou menos oculta ou subentendida.

Quando Sérgio constrói uma figura como a do bandeirante como um homem pobre e mestiço, em luta pela sobrevivência está intencionalmente desconstruindo, por meio da pesquisa histórica erudita, uma figura heroica, cuja construção fora baseada numa mobilização apologética do passado para fins políticos (FERRETTI 2008, p. 59-78). Nesta medida, pode-se afirmar que uma história outra, heterogênea e movediça (BLAJ; MALUF 1990, p. 17-46), de "figurantes mudos", ${ }^{3}$ se faz ao mesmo tempo que uma de caráter oficial ou apologético se desfaz. Isso é muito próximo da postura defendida explicitamente no prefácio à segunda edição de Visão do Paraíso, em que disse que não era função do historiador a "taumaturgia", o culto de um passado "posto no singular". Essa concepção foi contraposta pelo autor por uma história "exorcista", capaz de "afugentar do presente os demônios da história" (HOLANDA 1996, p. XVI).

Esta talvez seja a última etapa nesta análise da historicidade na interpretação do Brasil de Sérgio Buarque de Holanda. Se falamos de dois planos de historicidade ainda é necessário explicar como exatamente eles se articulam. O exemplo da figura do bandeirante é apenas ilustrativo e será aprofundado mais afrente. Antes disso, será necessário um novo interregno, pois, para compreender o mecanismo figural na temporalidade da interpretação do Brasil será necessário retomar a evolução do pensamento do autor no tempo, em particular seu percurso nos anos 1950, logo após a publicação da segunda edição de Raízes do Brasil e elaboração dos textos que compuseram Caminhos e Fronteiras.

\footnotetext{
3 "Para Sérgio Buarque de Holanda a principal tarefa do historiador consistia em estudar possibilidades de mudança social. Entretanto, conceitos herdados e intelectualismos abstratos impediam a sensibilidade para com o processo do devir. Raramente o que se afigurava como predominante na historiografia brasileira apontava um caminho profícuo para o historiador preocupado em estudar mudanças. Os caminhos institucionalizados escondiam os figurantes mudos e sua fala. Tanto as fontes quanto a própria historiografia falavam a linguagem do poder, e sempre imbuídas da ideologia dos interesses estabelecidos. Desvendar ideologias implica para o historiador um cuidadoso percurso interpretativo voltado para indícios tênues e nuanças sutis. Pormenores significativos apontavam caminhos imperceptíveis, o fragmentário, o não determinante, o secundário. Destes proviriam as pistas que indicariam o caminho da interpretação da mudança, do processo do vir a ser dos figurantes mudos em processo de forjar estratégias de sobrevivência" (DIAS 1998, p. 15).
} 


\section{Segundo interregno: os anos 1950 entre crítica literária e história}

No final de 1952, Sérgio Buarque embarcou para a Itália, a convite do Itamaraty, para lecionar na então recém-fundada Cátedra de Estudos Brasileiros da Universidade de Roma. Nos primeiros meses na cidade, antes que o curso se iniciasse, o autor aproveitou os arquivos e bibliotecas romanas para intensificar a escrita de um livro sobre a história da literatura colonial brasileira. A obra havia sido encomendada ainda na metade dos anos 1940 por Alvaro Lins para ser o primeiro volume de história da literatura brasileira editada por José Olympio. Fora o material levantando para a Antologia dos Poetas da Fase Colonial, publicada em 1952, é provável que Sérgio simplesmente não tivesse tido tempo de escrever a obra, coisa que não surpreende, dada a já mencionada demanda de trabalho no período. O texto só se tornou conhecido do público em 1991, quase dez anos depois de sua morte, graças ao empenho de Antonio Candido. Devido ao seu caráter fragmentário e inacabado, Candido batizou o livro de Capítulos de Literatura Colonial, fazendo referência aos Capítulos de História Colonial, de Capistrano de Abreu.

A primeira parte, "Poesia Épica" e se divide nos seguintes títulos, 1. O Ideal Heroico, 2. As Epopeias Sacras, 3. O Mito Americano e 4. A Arcádia Heroica. A segunda parte foi denominada posteriormente "Arcadismo" e se divide entre 1. O Ideal Arcádico e 2. Cláudio Manuel da Costa. O apêndice conta com dois textos aparentemente mais deslocados do conjunto: o primeiro, "Panorama da Literatura Colonial", é anterior a 1952 e fora do conjunto da história da literatura colonial (CANDIDO 1991, p. 12); o segundo é um rascunho sobre o padre Antônio Vieira. As primeiras páginas têm redação mais bem acabada, mas, à medida que se aproxima do fim, o texto vai se diluindo em apontamentos de pesquisa e comentários. Este texto provavelmente seria parte do conjunto de história da literatura e seria dotado de grande fôlego, já que teria de se equilibrar com o longo texto dedicado a Cláudio Manuel da Costa.

Mobilizando conhecimentos de teoria literária que acumulou ao longo do período em que foi crítico literário profissional, entre 1940 e o início da década seguinte, Sérgio rompe com uma divisão característica das histórias literárias desde o século XIX, marcada pela evolução linear e cronológica de estilos. Em substituição, o autor se preocupa com a própria historicidade do fazer literário, em suas palavras "situar cada obra em seu ambiente natural e na perspectiva histórica, determinar, em outras palavras, não o que significaria ela para o autor e a seus contemporâneos, mas, além disso, até que ponto conseguiu responder às exigências, aos apelos, em uma palavra, às 'perguntas' do público de seu tempo" (HOLANDA 1991, p. 287).

O texto ganha assim a dimensão de uma história cultural dedicada a narrar a dinâmica da apropriação de modelos literários europeus na América portuguesa. O padrão da análise segue as linhas mestras do pensamento buarqueano destacadas neste texto uma vez que a se pauta na dialética da adaptação de formas europeias no território americano. Dando um tratamento técnico à literatura, respeitando sua própria especificidade e historicidade, Sérgio Buarque aponta como resultado do processo adaptativo uma forma 
literária descrita pelo autor como "mito americano". Este conjunto de tópicas, lugares comuns literários, corresponde ao acervo descritivo próprio da América portuguesa ratificado como matéria poética a partir da adequação local de comuns literários ativamente circulantes na cultura ibérica barroca.

Em sua origem, os fragmentos retóricos que formarão progressivamente a forma autóctone do "o mito americano" se enquadram na estrutura discursiva do gênero épico. Este gênero é dedicado à narração da "ação heroica de tipos ilustres, fundamentando-a em princípios absolutos, força guerreira, soberania jurídico-religiosa, virtude fecunda" (HANSEN 2008, p. 19). A épica está diretamente ligada à legitimação do poder do estado em suas fundações divinas, em outras palavras, a épica é para Sérgio a expressão formal-literária da mentalidade do Antigo Regime (HANSEN 2008, p. 23). Sob este ponto de vista a literatura épica produzida no território português na América tem como função precípua legitimar e representar em discurso o "corpo místico" do Estado monárquico católico do reino de Portugal. Frente à introdução de padrões árcades e neoclássicos, que representam o mundo burguês modero em formação, a forma épica entra em crise, perde seu sentido. Nesta medida, os padrões arcaicos do antigo regime se dissolvem lentamente.

Assim, na visão da história da literatura de Sérgio Buarque de Holanda, as formas literárias autônomas da América portuguesa são produzidas no embate dialético entre dois mundos, um arcaico e um moderno. A forma literária autóctone nasce pela resistência do molde épico mesmo com a introdução dos padrões árcades. O "mito americano" pode ser considerado, portanto, um símbolo da precária inserção brasileira na modernidade, uma verdadeira marca de uma concepção arcaizante de poder e de estado, que caminha persistente até nossa formação nacional no século XIX. Essa tensão perpassa todas as análises literárias empreendidas no livro, incluindo as mais de 150 páginas dedicadas a Cláudio Manuel da Costa. Exatamente por isso, na medida em que seu texto ganhava fôlego, Sérgio cogitou transformá-lo na obra - A Era do Barroco no Brasil, que teria três volumes, segundo o anúncio das obras "em preparo" do autor tanto na terceira edição de Raízes do Brasil, de 1956, quanto na primeira edição de Caminhos e Fronteiras, de 1957. É oportuno lembrar que a identidade entre patriarcalismo e os modelos europeus barrocos foi uma das questões que embasaram sua crítica a Gilberto Freyre, em 1951, nas suas próprias palavras "A verdade é que muitos dos traços característicos desse patriarcalismo, em seu apogeu e em seu declínio, entre nós, mal se poderiam destacar dos modelos europeus e barrocos que se prolongaram até estas bandas do oceano" (HOLANDA 1979, p. 104).

Visão do paraíso, de 1958, foi apresentado como uma tese de cátedra de História da Civilização Brasileira, e sedimenta a tardia entrada do intelectual na Universidade de São Paulo (ocorrida em finais de 1956). Não surpreende que a obra tenha sido originalmente concebida como introdução à Era do Barroco no Brasil (GRAHAM 1982, p. 11). Tendo em conta que Capítulos de Literatura Colonial conta como padrões estéticos e ideias europeias foram adaptadas no novo território, Visão do Paraíso pode ser entendido como a verticalização 
de um caso específico - o da gênese da tópica edênica, dos primeiros anos da colonização à sua fixação como símbolo no imaginário americano. Afinal, compõem o mito americano lugares comuns caracterizados pela descrição das belezas naturais da terra, sendo dos mais importantes na sua formação aqueles relacionados com as paisagens bíblicas e de outras tradições religiosas do paraíso: localizado normalmente numa ilha, com o clima sem grande variação entre as estações, como numa primavera perene, os bosques resplandecentes com frutas abundantes e prados verdes e férteis, cheio de flores coloridas e cheirosas, o encontro de rios numa lagoa longínqua, repositora de riquezas em ouro ou de promessas como a juventude eterna (HOLANDA 1996, p. 176). ${ }^{4}$

Enquanto, nos domínios espanhóis, o mito do paraíso frutificou ganhando formas próprias e criativas, na América portuguesa o mito se assentou segundo o "realismo pedestre", a procura pelo enriquecimento predatório que caracterizava os colonizadores portugueses desde os tempos medievais. O mito assim raramente ganhava formas originais, e, assim como havia ocorrido no plano da cultura material com os bandeirantes e monçoeiros, assentava-se no plano do imaginário seguindo o princípio do desleixo; naquilo que o autor definiu como "atenuação plausível". Isto não impedia que a crença no mito do eldorado geograficamente tangível produzisse efeitos históricos concretos, já que foi certamente um dos fatores que contribuiu com o processo de expansão do território para muito além dos limites estabelecidos pelo Tratado de Tordesilhas.

\section{Uma imaginação histórica figural}

Talvez seja injusto reduzir a pesquisa erudita de Visão do Paraíso apenas às linhas mestras da interpretação do Brasil de Sérgio Buarque de Holanda. Este exercício pode acabar sufocando a especificidade da obra, caracterizada pela multiplicidade de vozes narrativas articuladas, insistentemente dedicadas a entrar em contato com um passado igualmente múltiplo, incerto e irredutível. Como notou mais de uma vez Laura de Mello e Souza, a própria inserção na obra de um capítulo final de tom conclusivo, coerente com a necessidade de uma tese, destoa do conjunto. Nem sempre Sérgio "intérprete do Brasil", formado na militância modernista, concorda com Sérgio scholar - mas esta tensão não deixa de ser parte das contradições que produzem o próprio autor. Para efeitos da compreensão de sua interpretação do Brasil estas contradições podem ser, na verdade, reveladoras; como é, por exemplo, a hesitante tentativa de elaboração de uma Era do Barroco no Brasil, a partir dos esboços que hoje conhecemos como Capítulos de Literatura Colonial e Visão do Paraíso.

Marcas dessa unidade original, que remete ao momento de revisão de Raízes do Brasil foram mantidas intencionalmente no texto de Visão do Paraíso como veremos a seguir, mesmo após as revisões realizadas para a primeira edição comercial do livro, de 1959, e na segunda edição, de 1968, que estabeleceu o texto que conhecemos. A passagem conclusiva da obra que segue abaixo condensa todos

\footnotetext{
${ }^{4} \mathrm{O}$ trecho referido sofreu modificações em relação à edição no formato tese, defendida em 1958 e corresponde à p. 190. Essas descrições contém várias reverberações das análises literárias dos épicos de Botelho de Oliveira, Francisco São Carlos, ou Frei Manuel Itaparica, realizadas em Capítulos.
} 
os elementos fundamentais do pensamento do autor ressaltados ao longo da minha argumentação: a protenção temporal que articula passado e futuro orientado pelo ainda, e o estabelecimento de um sentido predatório e negativo que se estabelece como herança na medida em que advém o Estado independente.

Teremos também os nossos eldorados. O das minas, certamente, mas ainda o do açúcar, o do tabaco, de tantos outros gêneros agrícolas, que se tiram da terra fértil, enquanto fértil, como o ouro se extrai até esgotar-se, do cascalho, sem retribuição de benefícios. E a procissão dos milagres há de continuar através de todo o período colonial, e não interromperá a Independência, sequer, ou a República (HOLANDA 1996, p. 367).

O sentido de herança traz à superfície uma avaliação negativa deste processo, uma verdadeira manifestação de discordância com os eventos já ocorridos; ou melhor, com o resto, a sobra, daquilo que já ocorreu contida no presente e que não cessará de ocorrer se nada for feito. Pode-se compreender a concepção buarqueana de uma história exorcista, que fala do passado induzindo a ação da consciência no presente. Neste caso, trata do mito do paraíso no processo de colonização dos séculos XVI e XVII ao mesmo tempo que critica sua acomodação como fundamento do imaginário nacional desde o final do século XVIII até os dias de hoje.

Trata-se, por isso, de uma imaginação histórica tecnicamente figural, como sugere Finazzi-Agrò (2005, p. 147). Figura é o "modo medieval de formar e interpretar alegoricamente, pelo qual uma ação ou personagem histórica é a prefiguração, no tempo, de uma ação posterior" (HANSEN 2006, p. 227), ou seja, a figura estabelece uma relação analógica entre planos de temporalidade que se comunicam alegoricamente: conta-se sobre um deles, ao mesmo tempo que se remete, em saltos, ao outro. Sergio Buarque de Holanda não é um caso único, pelo contrário, o recurso a este mecanismo intertextual na narrativa histórica é uma das características mais importantes da moderna historiografia do século XX (WHITE 1999; LAMBERT 2004). Esta estrutura ganha uma versão altamente refinada e criativa no pensamento do autor e condiciona a arquitetura temporal de sua interpretação histórica em dois planos: o da dialética entre elementos ibéricos e elementos autóctones no processo de colonização, articulado figurativamente à análise do reaproveitamento desses elementos, dispostos como herança na formação do Estado e da nação brasileiros, processo ocorrido ao longo do século XIX e que se desdobra até o momento em que vivem os intelectuais.

Projetar o desenvolvimento do pensamento de Sérgio Buarque de Holanda no tempo, resistindo frequentemente ao sentido de unidade muitas vezes impostos pelas camadas de revisão sobre o texto, pode revelar de modo mais claro o seu pensamento na interpretação do Brasil. Ainda é bastante discutível se ele pode ser projetado como 'o pensamento do autor' definitivo. Apesar de parecer que ele representa um todo, muitas vezes induzidos pela ação do próprio autor, reduzindo ao essencial, a trajetória mapeada neste texto é de cerca de dez anos, entre 1948, segunda edição de Raízes do Brasil e a defesa 
de Visão do Paraíso. Depois deste momento, com a entrada definitiva de Sérgio na Universidade de São Paulo, seu pensamento certamente evoluiu e muitas dessas considerações identificadas aqui foram revistas. Entretanto, como apontei anteriormente, os mecanismos temporais estudados neste texto nunca foram abrandados, e tornam-se evidentes identificando muitos dos ecos que um texto deixou sobre outro.

Esta questão é particularmente interessante no caso da relação entre Visão do Paraíso e Capítulos de Literatura Colonial. O "mito edênico" é o aprofundamento do desenvolvimento do "mito americano". O resultado da projeção destes dois textos em perspectiva é que sua gênese comum permite revelar com mais clareza a ligação entre o mito edênico e o desenvolvimento de formas nacionais, e assim também permite enxergar com um pouco mais de clareza o ponto de encontro dos dois mecanismos temporais articulados figurativamente. A passagem conclusiva que, destacada de sua tese, começa como "teremos também nossos eldorados" tem o papel de núcleo irradiador do problema justamente porque ela brota dessa intersecção, dramatizada literariamente na alma cindida em dois mundos de Cláudio Manuel da Costa. Nas palavras de Sérgio em Capítulos de Literatura Colonial,

Antes de terminar o poema, ainda uma vez falará Itamonte a Albuquerque, fazendo-Ihe ver o plano da futura povoação e dos seus mais nobres monumentos: o pelourinho, no meio da régia praça, a torre do relógio, as pontes, as fontes e os chafarizes de mármore, os templos "em que hão de esgotar tantos erários" e principalmente a Casa da Cadeia e a Câmera. Nesta já entra o herói e, ao penetrar na sala do senado, enquanto manda lavrar a escritura formal da vila, recebe do pátrio gênio, por mãos de destro artífice pintados nas paredes, a oferta das montanhas do país "por ordem natural, clara e distinta", dos trabalhos vários com que extrai o mineiro o cascalho, ou se ocupa de penetrar o duro monte, em busca de metal louro e ainda com que, num país onde a,

Força dos bois não geme ao grave arado,

Só do bom lavrador braço armado

Derriba os matos, e se ateia logo

Sobre a seca matéria, o ardente fogo.

Não faltam nas pinturas a cana loura, nem o tabaco ou a bananeira, que, seguindo expressamente a lição de Milton - lido pelo poeta em versão francesa -, é assimilada à figueira que causou, no Éden, a perda dos nossos primeiros pais, ou ainda os pássaros (HOLANDA 1991, p. 169).

O anúncio profético que faz Sérgio Buarque de Holanda no final de Visão do Paraíso remete por analogia figural, como num jogo de espelhos, para outro anúncio profético, o da Fábula do Ribeirão do Carmo - de uma opulenta cidade construída na beira do rio barrento - da mesma parábola de nossa própria formação tão bem caracterizada em seu livro de estreia. Uma sociedade que nasce na margem do processo de colonização, fruto do desleixo e de um certo abandono, de um estranho conluio entre arcaico e moderno e de sua herança no processo de formação do Estado e da nação. Interpretação que, como vimos, é resultante de uma arquitetura temporal debatida e construída, que fundamenta 
a tradição brasileira de pensamento do século XX em que fomos formados. Assim como ocorre com a permanência do passado arcaico em Raízes do Brasil, só seremos capazes de superá-la, compreendendo-a melhor em sua historicidade, desnaturalizando suas marcas relegadas em nosso próprio olhar.

\section{Referências bibliográficas}

AGAMBEN, Giorgio. Il Tempo che Resta: un Commento alla Lettera ai Romani. Torino: Bollati Boringhieri, 2000.

BLAJ, Ilana; MALUF, Marina, Caminhos e fronteiras: o movimento na obra de Sérgio Buarque de Holanda, Revista de História, São Paulo, n. 122, janjun., 1990.

CANDIDO, Antonio. Prefácio. In: HOLANDA, S. B. Capítulos de Literatura Colonial. São Paulo: Brasiliense, 1991.

CARVALHO, Marcus Vinicius Corrêa. Outros Lados: Sérgio Buarque de Holanda, Crítica Literária, História e Política. Campinas: IFCH-Unicamp, tese de Doutorado em história, 2003.

DIAS, Maria Odila L. S. Sérgio Buarque de Holanda e o Brasil. São Paulo: Editora Fundação Perseu Abramo, 1998.

EUGÊNIO, João Kennedy. Ritmo espontâneo: o organiscismo em Raízes do Brasil de Sérgio Buarque de Holanda. Teresina: EDUFPI, 2011.

FERRETTI, Danilo Zioni. O uso politico do passado bandeirante: o debate entre Oliveira Vianna e Alfredo Ellis Jr. (1920-1926). Estudos Históricos, Rio de Janeiro, vol. 21, no 41, janeiro-junho de 2008.

FINAZZI-AGRÒ, Ettore. A trama e o texto. In: PESAVENTO, Sandra. J. Um

historiador nas fronteiras: o Brasil de Sérgio Buarque de Holanda. Belo Horizonte: Editora UFMG, 2005.

GOLDFEDER, André; WAIZBORT, Leopoldo. Sobre os tipos em Raízes do Brasil, Revista do IEB, n. 49, setembro de 2009.

GRAHAM, Richard. An Interview with Sérgio Buarque de Holanda. Hispanic American Historical Review (HAHR), Austin, vol. 62, n. 1, fev. 1982.

HANSEN, João Adolfo. Alegoria. Construção e Interpretação da Metáfora. São Paulo; Campinas: Hedra/Editora da Unicamp, 2006. . Notas sobre o Gênero Épico. In: Épicos - Coleção Multiclássicos vol. 1. Organização e apresentação de Ivan Teixeira. São Paulo: Edusp, 2008.

HOLANDA, Sérgio Buarque de. Raízes do Brasil. $1^{\text {a }}$ ed. Rio de Janeiro: José Olympio, 1936.

. Au Brésil colonial: Les civilizacions du miel, Annales, 5e année, n. 1, janvier-mars 1950. 
. Visão do Paraíso: Os Motivos Edênicos no Descobrimento e Colonização do Brasil. São Paulo, FFCL/USP, 1958.

Tentativas de Mitologia. São Paulo: Perspectiva, 1979.

. Capítulos de Literatura Colonial. São Paulo: Brasiliense, 1991.

. Visão do Paraíso: Os Motivos Edênicos no Descobrimento e Colonização do Brasil. 6a ed. São Paulo: Brasiliense, 1996.

. A Herança Colonial: Sua Desagregação. In: História Geral da Civilização Brasileira. T. II, vol.1. São Paulo: Difel, 1961.

KOSELLECK, Reinhart. Futuro Passado: contribuição à semântica dos tempos históricos. Rio de Janeiro: Contraponto; Editora PUC Rio, 2006.

LAMBERT, Greg. The Return of the Baroque in Modern Culture. London; New York: Continuum, 2004.

MONTEIRO, Pedro Meira. A queda do aventureiro: aventura, cordialidade e os novos tempos em Raízes do Brasil. Campinas: Editora da Unicamp, 1999.

NICODEMO, Thiago Lima. Urdidura do Vivido: Visão do Paraíso e a obra de Sérgio Buarque de Holanda nos anos 1950. São Paulo: Edusp, 2008.

Alegoria moderna: consciência histórica e figuração do passado na crítica literária de Sérgio Buarque de Holanda. Tese (Doutorado em História Social). Programa de Pós-Graduação em História Social, Universidade de São Paulo, São Paulo, 2011.

. Sergio Buarque de Holanda. In: SECCO, Lincoln; PERICÁS, Luiz Bernardo (orgs.). Intérpretes do Brasil: clássicos, rebeldes e renegados. São Paulo: Boitempo, 2014, p. 141-156.

ROCHA, João Cezar de. O Exílio como Eixo: Bem-sucedidos e Desterrados. In: MONTEIRO, Pedro Meira; EUGÊNIO, João Kennedy (orgs.). Sérgio Buarque de Holanda: Perspectivas. Campinas/Rio de Janeiro. Editora da Unicamp/Editora da UERJ, 2008.

VECCHI, Roberto. Atlas intersticial do tempo do fim: Nossa Revolução. In: PESAVENTO, Sandra. J. Um historiador nas fronteiras: o Brasil de Sérgio Buarque de Holanda. Belo Horizonte: Editora UFMG, 2005.

WEGNER, Robert. A conquista do oeste: a fronteira na obra de Sérgio Buarque de Holanda. Belo Horizonte: Editora UFMG, 2000.

WHITE, Hayden. Figural Realis: Studies in The Mimesis Effect. Baltimore. Md. Johns Hopkins University Press, 1999. 